A numerical study of the effects of primary reference fuel chemical kinetics on ignition and heat release under homogeneous reciprocating engine conditions

Mohammad Fatouraie ${ }^{a,}$, Darshan M.A. Karwat ${ }^{a}$, and Margaret S. Wooldridge ${ }^{a, b}$

${ }^{a}$ Department of Mechanical Engineering, University of Michigan,

Ann Arbor, Michigan 48109-2125, USA

${ }^{b}$ Department of Aerospace Engineering, University of Michigan,

Ann Arbor, MI 48109-2125, USA

* Corresponding author:

University of Michigan

Department of Mechanical Engineering

2350 Hayward Street, Ann Arbor, Michigan, USA 48109-2125

Fax: 734-647-3170, Voice: 734-763-7470

E-mail address: mohfat@umich.edu

Type of article: Full length 


\title{
A numerical study of the effects of primary reference fuel chemical kinetics on ignition and heat release under homogeneous reciprocating engine conditions
}

\author{
Mohammad Fatouraie, Darshan M.A. Karwat, Margaret S. Wooldridge
}

\begin{abstract}
In the current work, numerical simulations are used to evaluate the effects of detailed reaction chemistry of different primary reference fuel (PRF) blends of iso-octane and $n$-heptane on heat release in one-dimensional engine simulations. A simplified slider-crank model was used to represent the engine cycle. The contributions of specific reaction classes to ignition and heat release were quantified. Maps of ignition phasing and heat release were created as a function of pressure and temperature to indicate the change in reactivity (defined by the first and second stages of ignition) as a function of state conditions as well as the fraction of heat release associated with the two stages of ignition. For the conditions studied, the reactivity of the second stage of ignition always increased with increasing temperature, i.e. the phasing of autoignition advanced with increasing temperature, whereas the reactivity of the first stage of ignition exhibited negative temperature dependence where increasing temperature delayed the first stage of ignition and decreased the heat release at the first stage of ignition for some conditions. The results show low temperature chemistry radicals like $\mathrm{C}_{7} \mathrm{RO}_{2}$ species are not uniquely indicative of low temperature heat release, but they are formed at earlier times, higher rates and higher concentrations with PRF blends with higher fractions of $n$-heptane. A modified approach to the Livengood-Wu integral is presented to capture the integrated effects of the compression stroke on the potential for using the first stage of ignition to distribute heat release. The results of the modified ignition integral analysis are presented as a function of engine speed and fuel/air preheat temperature and demonstrate the utility of the approach to design and interpret fueling strategies of fuel blends.
\end{abstract}

Keywords: iso-octane; $n$-heptane; primary reference fuel blends; detailed chemical kinetics; numerical simulation 


\section{Introduction}

Modern internal combustion engines operate at low temperatures and with high levels of dilution; conditions where heat release is often affected by low-temperature fuel chemistry. In particular, homogeneous charge compression ignition (HCCI) is a low temperature combustion strategy that has successfully yielded high thermal efficiencies and low emissions [1 and references therein]. Relying on fuel chemical kinetics rather than a spark for ignition, HCCI remains difficult to control [1-4] and therefore difficult to develop for commercial powertrains. But the HCCI operating mode provides an opportunity to consider fuel chemistry effects on engine performance at conditions particularly sensitive to combustion chemistry and where chemistry dominates the rate of heat release, as compared with strategies where heat release rate is controlled by fuel/air mixing and flame propagation convolved with reaction chemistry. The results of autoignition studies also provide understanding of pre-ignition and end-gas knock phenomena.

Many studies have considered the effects of primary reference fuel (PRF) blends of $n$-heptane and iso-octane on HCCI engine performance [1 and references therein] and on the relationship between PRF blends, octane number and engine knock [5]. Some outcomes of these studies demonstrate sensitivity to PRF blends that are attributed to differences in the reaction pathways important for $n$-heptane (PRF0) and iso-octane (PRF100). For example, blends with low PRF number (i.e. large fractions of $n$-heptane in the fuel blend, where the PRF number indicates the volume fraction of iso-octane in the binary fuel blend), which exhibit more low temperature heat release, have been found to be more sensitive to partial fuel stratification, and are thus more effective at decreasing the rate of pressure rise during the HCCI [6,7].

Simultaneous to the development of the understanding of PRF engine performance at HCCI operating conditions, the elementary chemical kinetics of $n$-heptane and iso-octane have been explored at length using many experimental and computational methods [e.g. [8-20], and references therein]. These studies have carefully and systematically elucidated the reactions controlling low- and high-temperature heat release, as well as the reactions responsible for negative temperature coefficient (NTC) behavior. While several studies include detailed reaction mechanisms in simplified engine simulations, what remains elusive are the connections between elementary reaction chemistry and engine performance metrics. Some key contributions to the literature on this topic include the work by Silke et al. [2] and Mehl et al. [16-19]. In one of the earlier studies by Mehl and co-workers [16], the authors used detailed reaction chemistry and a simplified engine model for a range of pentane and pentene fuel blends to study the effects of a range of research and motoring octane numbers on fuel reactivity. Importantly, Mehl et al. [16] superimposed pressure-temperature trajectories for different engine conditions on reactivity maps (defined by ignition delay times), providing insight into when state conditions in the engine overlap with NTC regions of the fuels. In Silke et al. [2], detailed reaction chemistry was used to quantify low 
temperature heat release as a function of boosted intake air pressure and compared with HCCI engine data for a PRF80 fuel blend. Reaction path and sensitivity analyses were used to identify the classes of reactions important for forming $\mathrm{OH}$ and for phasing of the low temperature heat release. In Mehl et al. [17], measured intermediate species were well predicted using detailed chemistry for PRF20 blends. In another study, Mehl et al. [18] compared predicted and measured phasing to low temperature heat release using detailed chemistry for a range of PRF blends and for different generations of PRF reaction mechanisms.

Because reciprocating engines create wide-ranging trajectories of temperature and pressure conditions during their cyclical operation, it is challenging to extrapolate the results of the many high-quality isothermal and/or isobaric studies of PRF reaction chemistry to engine behavior. Building on the methods used in the simplified HCCI engine modeling studies like those by Silke et al. [2] and Mehl et al. [16], the objective of this work was to identify links between elementary reaction chemistry for PRF blends and engine performance metrics using a simplified engine modeling approach and focusing on the cumulative effects of the temperature/ pressure trajectories on heat release at chemically limited operating conditions. A simplified slider/crank model was used with a detailed chemical kinetic model for PRF blends to simulate a reciprocating engine compression process. The results were analyzed to determine the relative contributions of individual as well as groups of chemical reactions to engine performance metrics such as ignition phasing. Additionally the behavior of the combustion intermediates was evaluated to determine if sentinel species could be identified as proxies for low temperature heat release.

\section{Technical Approach}

As noted above, significant efforts have been made for developing detailed chemical kinetic mechanisms for the primary reference fuels $n$-heptane and iso-octane, and several mechanisms focus on high-temperature chemistry (see, for example, [20]). Many mechanisms incorporate low-temperature kinetic schemes making them applicable over wider temperature ranges. Comprehensive explanations of the development and validation of these reaction mechanisms can be found elsewhere (see, for example, [8-10,14,15,18,19] among others). Researchers at Lawrence Livermore National Laboratories (LLNL) have recently incorporated the detailed kinetics of large linear alkenes into their PRF mechanism [19], and have also added cross-reactions between large fuel molecules and fuel fragments (for example, $n$ heptyl + iso-octane). Research by Vanhove et al. [21] and others has shown these cross reactions between fuel fragments and fuel molecules are important determinants of whether detailed mechanisms can adequately represent global reactivity of fuel/oxidizer mixtures. Consequently, the LLNL reaction mechanism was selected for the present study. 
The LLNL mechanism consists of a $\mathrm{C}_{1}-\mathrm{C}_{4}$ detailed mechanism core with three additional blocks of reactions, including reaction pathways for saturated and unsaturated linear hydrocarbons through $\mathrm{C}_{7}$ as well as similar reactions for branched hydrocarbons from $\mathrm{C}_{5}$ to $\mathrm{C}_{8}$, along with aromatic hydrocarbon reactions. Reactions of small radicals with alkyl $(\mathrm{R})$ and alkylperoxy radicals $\left(\mathrm{RO}_{2}\right)$ from different fuels are also included. These reactions determine the low-temperature reactivity of PRFs (see, for example, [8-10,14,15 among other numerous references].

The LLNL mechanism has been built gradually and improved upon consistently with the availability of new studies of computational chemistry and new experimental data for validation and verification. (For details on this effort of continuous improvement, please see [22].) The mechanism has been validated over a range of conditions and for diverse data sets as seen in the literature. The goal of this work was not to further validate the detailed chemical kinetic model, but rather to use our understanding of detailed reaction schemes represented in the model to understand the sensitivity of the engine simulations to various PRF blends and engine operating conditions.

The CHEMKIN suite of software (version 10131, x64 [23]) was used for the two categories of simulations performed and presented in this paper. First, adiabatic constant volume simulations were used to quantify the ignition characteristics of the fuel blends, and second, adiabatic variable volume simulations were used to simulate the dynamic state conditions of the crank-slider approach of engine simulations. The results of the effects of varying the initial state conditions and engine conditions are presented below.

\section{Results and Discussion}

\subsection{Constant Volume Autoignition Characteristics of PRF blends}

Calculations of constant volume, adiabatic ignition delay times provide a baseline understanding of the ignition characteristics of the fuels as a function of temperature, pressure and mixture conditions. While many such results can be found in the literature, the trends are briefly reviewed here to provide a basis of comparison with the results of the variable volume simulations. The ignition delay time characteristics of four PRF blends-PRF0, PRF60, PRF88 and PRF100 — over the temperature range of 625 to $1200 \mathrm{~K}$, at pressures of 10 and 25 bar with an equivalence ratio $(\phi)$ of 0.33 and inert $/ \mathrm{O}_{2}$ ratio of 3.76 are presented in Fig. 1. The lean equivalence ratio was selected due to the relevance to HCCI engine operation [1]. $\mathrm{CO}_{2}$ and $\mathrm{H}_{2} \mathrm{O}$ comprised a total of $5 \%$ of the diluent gas composition for all simulations to incorporate the effect of internal exhaust gas recirculation (EGR) of an engine. The balance of the diluent gas composition was $\mathrm{N}_{2}$. The EGR values were selected based on estimates for internal residual for a single-cylinder CFR engine [24]. The pressures of the calculations span the range expected during the compression stroke of wide-open-throttle operation of an engine with a compression ratio of 12:1. 
As expected and as seen in Fig. 1, the ignition of PRF100 is significantly slower than that of PRF0 at the same pressure for temperatures below $\sim 1000 \mathrm{~K}$. The results in Fig. 1 also demonstrate the predicted magnitude of non-Arrhenius behavior of the blends at different state conditions. For some fuel blends and conditions, the non-Arrhenius behavior is significant and negative temperature coefficient trends are predicted, i.e. where increasing temperature results in lower fuel reactivity. The NTC regime occurs at lower temperatures for iso-octane compared with $n$-heptane, and the NTC region shifts to higher temperatures with increasing pressure. Two stages of heat release are observed in the low temperature portion of the non-Arrhenius regions. For these cases, the first stage of ignition is defined by the first local maximum in the rate of pressure rise in the simulations and is represented by open symbols and dotted lines in the figure. The second stage of ignition, also referred to as autoignition in this work, is defined by the maximum rate of pressure rise in the simulations and is represented by closed symbols and solid lines. Two stage ignition is generally observed at temperatures less than $875 \mathrm{~K}$. Definitions of the first and second stages of ignition for typical simulation time histories are provided in the supplementary material. Importantly, the time difference between the first and second stage of ignition is not constant in the NTC region, and the temperature corresponding to the maximum time difference is different for each pressure and fuel blend. As seen in Fig. 1, adding iso-octane to the PRF blend not only increases the overall ignition delay time non-linearly, but also non-linearly increases the difference between the first and second stages of ignition. These results are attributed to the high degree of branching in iso-octane, which increases the number of primary carbon sites in the molecule, thus decreasing the availability of lower energy secondary and tertiary $\mathrm{C}-\mathrm{H}$ bonds that promote low-temperature chemistry, as described below.

The NTC behavior of fuel species like $n$-heptane and iso-octane is attributed to low-temperature reaction kinetics. These kinetic pathways produce a large number of radicals at low temperatures, thereby accelerating fuel consumption and global ignition. Several papers (such as[8,9]) articulate the kinetics comprehensively. Fig. 2, based on the work by Curran et al. [8], is a schematic of the high- and lowtemperature chemistry pathways that lead to two-stage ignition and faster global reactivity at lower temperatures. The brief discussion below pertains to PRF0 at 10 bar (solid red line) presented in Fig. 1. Analogous descriptions of PRF100 can be made, and at a very high level, any mixture of $n$-heptane and iso-octane, i.e. any PRF blend other than PRF0 or PRF100, can be described by the individual $n$-heptane and iso-octane reaction pathways, except for the addition of the cross reactions between fuel fragments. See for example the work of Vanhove et al. [21].

At high temperatures (above approximately $875 \mathrm{~K}$ for PRF0 at $10 \mathrm{bar}$ ), $\mathrm{R}$ (alkyl) radicals formed during early times undergo $\beta$-scission. $\beta$-scission is the breaking of the $\mathrm{C}$ - $\mathrm{C}$ bond one removed from the radical carbon site. Taking $\mathrm{C}_{7} \mathrm{H}_{15}-2$, for example, the second $\mathrm{C}$ atom in the alkyl chain is missing a 
hydrogen atom. At high temperatures, $\beta$-scission of $\mathrm{C}_{7} \mathrm{H}_{15}-2$ yields propene and the radical $\mathrm{PC}_{4} \mathrm{H}_{9}$. $\beta$ scission is a chain-propagating reaction pathway, and the main chain branching reaction at high temperatures is $\mathrm{H}+\mathrm{O}_{2}=\mathrm{O}+\mathrm{OH}$. This general reaction pathway is represented in the top part of Fig. 2 .

In the low temperature region, (temperatures below $\sim 700 \mathrm{~K}$ for PRF0 at 10 bar), $\mathrm{O}_{2}$ molecules add to the $\mathrm{R}$ radical site, and internal isomerization of 5-, 6-, and 7-member transition-state rings leads to the formation of QOOH radicals. For example, $\mathrm{C}_{7} \mathrm{H}_{15}-2$ radicals may combine with $\mathrm{O}_{2}$ to yield $\mathrm{C}_{7} \mathrm{H}_{15} \mathrm{O}_{2}-2$ radicals, which then isomerize to form $\mathrm{C}_{7} \mathrm{H}_{14} \mathrm{OOH} 2-1, \mathrm{C}_{7} \mathrm{H}_{14} \mathrm{OOH} 2-3, \mathrm{C}_{7} \mathrm{H}_{14} \mathrm{OOH} 2-4, \mathrm{C}_{7} \mathrm{H}_{14} \mathrm{OOH} 2-5$, or $\mathrm{C}_{7} \mathrm{H}_{14} \mathrm{OOH} 2-6$. The QOOH radicals decompose to yield stable compounds (olefins, cyclic ethers, ketenes) and a radical $\left(\mathrm{HO}_{2}\right.$ or $\left.\mathrm{OH}\right)$. These low- temperature reaction kinetics are chain propagating.

In the NTC region or between $\sim 700 \mathrm{~K}$ to $875 \mathrm{~K}$ for PRF0 at $10 \mathrm{bar}$, QOOH radicals do not undergo chain propagating reactions, but rather add $\mathrm{O}_{2}$ to the reaction site, forming $\mathrm{O}_{2} \mathrm{QOOH}$ radicals. These radicals then decompose through a transition-state ring to produce a ketohydroperoxide and an $\mathrm{OH}$ radical. The decomposition of the ketohydroperoxide forms another $\mathrm{OH}$ radical and a carbonyl radical, and thus, crucially, reaction kinetics in this intermediate temperature range are chain branching rather than chain propagating. For example, $\mathrm{C}_{7} \mathrm{H}_{14} \mathrm{OOH} 2-1$ radicals combine with $\mathrm{O}_{2}$ to yield $\mathrm{C}_{7} \mathrm{H}_{14} \mathrm{OOH} 2-1 \mathrm{O}_{2}$, forming $\mathrm{NC}_{7} \mathrm{KET} 21+\mathrm{OH}$. $\mathrm{NC}_{7} \mathrm{KET} 21$ then decomposes, eventually forming $\mathrm{CH}_{3} \mathrm{COCH}_{2}$ and $\mathrm{OH}$. The chain branching accelerates fuel and fuel fragment oxidation. It is also important to note the exothermicity of this reaction pathway increases the temperature of the system demarking the first stage of ignition. The increase in temperature also slows the reactions that form ketohydroperoxides. Between the first and second stages of ignition, an accumulation of $\mathrm{H}_{2} \mathrm{O}_{2}$ radicals occurs, and the decomposition of $\mathrm{H}_{2} \mathrm{O}_{2}$ creates two $\mathrm{OH}$ radicals, which then lead to thermal runaway and autoignition.

As in the modeling studies by Yates et al. [25] and Mehl et al. [16], the data of Fig. 1 can be converted to contour maps of the ignition delay time as a function of pressure and temperature for the different fuel blends. Fig. 3 presents the contour surfaces for PRF0 and PRF100 where the top panels present the data for the first stage of ignition and the bottom panels present the data for autoignition. In order to generate the contours, a series of simulations for a range of temperatures and pressures were performed. The pressure was varied from 5 bar to 25 bar using 5 bar intervals and the temperature was varied from $600 \mathrm{~K}$ to $1200 \mathrm{~K}$ using $25 \mathrm{~K}$ intervals. The conditions yielding ignition delay times longer than $600 \mathrm{~ms}$ were eliminated. Presenting the data in this manner allows the trajectory of a compression stroke to be superimposed on the ignition delay time data, as depicted by the dashed line in Fig. 3. The compression stroke shows the trajectory of states that occurs during isentropic compression, in this case for a fuel/air mixture with $\phi=0.33$, an intake temperature of $T_{\text {in }}=423 \mathrm{~K}$, an intake pressure of $P_{\text {in }}=1$ bar and for a compression ratio $C R=12$. (High levels of air preheat are necessary for appropriate HCCI engine phasing.) As seen in the bottom panels for both PRF0 and PRF100, at every point along the $C R=$ 
12 trajectory, increasing compression decreases the autoignition delay time. However, the trajectory passes through thermodynamic states in which PRF0 exhibits NTC behavior, where increasing compression (and therefore temperature and pressure) increases the time to the first stage of ignition. PRF100 shows very little NTC or two stage ignition behavior along the $C R=12$ trajectory.

In engines, the amount of heat release at the first stage of ignition affects the load range of HCCI combustion by distributing the heat release and reducing the pressure rise rate [6]. Fig. 4. presents the fractional heat release at the first stage of ignition for PRF0 and PRF100 using contour maps similar to Fig. 3 and including the compression stroke trajectory of Fig. 3. The fraction of the total heat release was calculated at the midpoint of the time between the first and second stages of ignition. The figures show for a constant temperature, the amount of heat released during the first stage of ignition increases as pressure increases. The results also show a maximum of $30 \%$ of the total heat release can occur at the first stage of ignition for PRF0 and a maximum of $18 \%$ can occur with the first stage of ignition for PRF100. However, when the compression stroke is considered, less than $18 \%$ of the overall heat release is associated with the first stage of ignition for PRF0. The value of $18 \%$ represents an upper limit for PRF0 for the heat release, since the fuel/air mixture would need sufficient residence time at the NTC temperature and pressure conditions for reaction to occur. For PRF100, negligible heat release is associated with the first stage of ignition for the compression stroke considered here and using the definition for measuring heat release based on the midpoint in time between the first and second stages of ignition.

\subsection{Variable Volume Autoignition Characteristics of PRF blends}

In this section, the results of a simple slider-crank model with detailed chemistry are used to understand the cumulative effects of compression and finite reaction times on ignition phasing and heat release. Heat transfer and turbulence effects are neglected to isolate the chemical effects of the PRF blends, and the results thus represent the effects of fuel chemistry at the limiting conditions of fully premixed fuel/air mixtures.

The dimensions of a single cylinder cooperative fuel research (CFR) engine with a $83 \mathrm{~mm}$ bore and a $114 \mathrm{~mm}$ stroke (as used in the HCCI engine study by Rapp et al. [26]) were used to simulate a range of compression ratios and intake temperatures for a fixed intake pressure of 1 bar with equivalence ratio of $\phi=0.33$ and air dilution including 5\% EGR, as described earlier. The engine speed was set to 600 RPM (unless otherwise noted), a standard operating condition for research octane number (RON) rating exercises. The simulations were initiated using the temperature and pressure conditions expected in the CFR engine configuration at intake valve closing. The volume profile was derived using the compression ratio specified at the beginning of the simulation. 
First, the slider-crank model predictions were evaluated to ensure the results reproduced experimentally observed trends from the HCCI engine study of primary reference fuels by Rapp et al. [26]. In Rapp et al. [26], the compression ratio of the engine was varied for each PRF blend to determine the time of $50 \%$ of the total heat release. This time is defined as CA50 and is reported in crank angle degrees. CA50 is typically determined using in-cylinder pressure time history measurements and heat release analysis [27], and is often used as a metric to gauge optimum timing for heat release rate and as a measure of the ignition delay time for HCCI operating conditions. Fig. 5 compares the results of CA50 values from Rapp et al. [26] with the simulation results. The simulation results exhibited almost instantaneous heat release at the second stage of ignition, making the CA50 and the phasing of peak pressure rise rate, $\mathrm{d} P / \mathrm{d} \theta_{\max }$, equivalent for the simulations.

Both the modeling and the experimental results show maintaining combustion phasing within a narrow range of crank angle degree (CAD) while increasing the PRF number requires increasing the CR, which is expected given the slower reactivity of iso-octane compared with $n$-heptane. The experimental trends are well reproduced by the simplified model for the range of PRF blends studied with the exception of the more advanced ignition predicted by the simulations for PRF88 compared with PRF85. The experimental trend indicates comparable ignition timing for PRF88 and PRF 85. Differences between the absolute values for the experimental data and the model results are expected, since the model neglects heat losses, friction, turbulence-kinetic interactions, and stratification, to name a few physical phenomena important in the engines studies. At higher compression ratios, the friction and heat losses will increase considerably in the engine which may be the source of the discrepancy between the model predictions and the experimental data for PRF88.

Having verified that the model can reasonably reproduce the experimental trends observed in the literature, the following sections examine the contributions of the detailed reaction chemistry to the engine model predictions. Fig. 6 presents the model predictions for the time-histories of pressure, accumulated heat release, temperature, and fraction of fuel consumed for a range of PRF blends for $C R$ $=12, T_{\text {in }}=423 \mathrm{~K}, P_{\text {in }}=1$ bar, $\phi=0.33$, and air level of dilution including 5\% EGR. A first stage of ignition was identified for a PRF blend if there was a $5 \%$ increase in pressure during compression compared to a motoring (i.e. non-reacting) baseline. Autoignition or the second stage of ignition was determined based on the peak rate of pressure rise. As the amount of $n$-heptane in the fuel blend decreases with increasing PRF number, the heat release associated with the first stage of ignition decreases and is more distributed in time. Further, the results of the slider-crank simulations highlight the effects of the finite reaction and compression time compared with the constant volume results. Recall, Fig. 4 indicates a maximum of $18 \%$ of the heat release associated with the first stage of ignition for PRF0 and the $C R=12$ trajectory for fixed state conditions. The engine simulations show only half of the 
maximum heat release, $\sim 9 \%$, occurs for PRF0, and this heat release corresponds to consumption of $70 \%$ of the $n$-heptane. For the PRF100 condition, fuel consumption begins close to top dead center (TDC), and consequently the expansion stroke essentially quenches the reactivity of PRF100, limiting fuel consumption to around $40 \%$ and resulting in no significant heat release.

For all the PRF blends, the fraction of $n$-heptane consumed (solid lines) at the first stage of ignition is systematically higher than the fraction of iso-octane consumed (dashed lines). As seen in Fig. $\mathbf{3}$ and as indicated by the PRF100 data in Fig. 6, iso-octane has very low reactivity at these conditions, thus the consumption of iso-octane in the blends is attributed to the radical pool developed by the consumption of $n$-heptane. Such synergistic fuel interactions have been observed with constant volume studies with other binary blends of fuels of different reactivity (e.g. Vanhove et al.[21] and Karwat et al. [28]), where the radicals produced by the more reactive fuel induce the other fuel to react at conditions where it would normally be non-reactive. For the blends, the accumulated heat release at the first stage of ignition decreases with increasing PRF number. Increasing the amount of iso-octane in the fuel blend decreases the rate of fuel consumption, and when CA50 occurs after TDC, the cooling effect of stroke expansion further slows the rate of fuel consumption and distributes the heat release over a longer duration.

The trends for heat release can be explained by the reaction pathways that dominate for the different PRF blends. While the reaction pathways for $n$-heptane and iso-octane are broadly analogous given that they are both alkanes, their respective rates of low-temperature chemistry reactions, described above, are functions of the number of primary, secondary and tertiary bonds in each molecule. More primary $\mathrm{C}-\mathrm{H}$ bonds leads to a lower amount of low-temperature chemistry at a given temperature and pressure. In Fig. 7, the heat production per reaction is presented for the PRF60 blend simulation of Fig. 6. All reactions are included in the figure and the four most exothermic and endothermic reactions are highlighted. The left and right panels present the data for the first and second stages of ignition, respectively. At the first stage of ignition, the interplay between exothermic reactions like $\mathrm{C}_{7} \mathrm{H}_{15} \mathrm{O}_{2}-3=\mathrm{C}_{7} \mathrm{H}_{15}+\mathrm{O}_{2}$ and endothermic reactions like $\mathrm{NC}_{7} \mathrm{KET} 24=\mathrm{CH}_{2} \mathrm{O}+\mathrm{CH}_{3} \mathrm{COCH}_{2}+\mathrm{OH}$ dictate the magnitude of the lowtemperature chemistry and the low temperature heat release (LTHR). The left panel of Fig. 7 confirms the low-temperature chemistry of $n$-heptane that plays a more dominant role in low-temperature heat release (LTHR) in engine conditions. As described above, the heat release at the first stage of ignition suppresses the $\mathrm{RO}_{2}$ and QOOH chemistry, and, as seen in the right panel of Fig. 7, it is small radical chemistry that leads to the heat release and chain branching necessary for autoignition. In comparison, only a single stage of heat release and ignition is observed for PRF88 (see Fig. 6), and the reactions controlling heat release for PRF88 (not shown here) were the same as those for heat release of autoignition of PRF60, i.e. the reactions found in the right panel of Fig. 7. 
Fig. 8 presents the predicted time histories of the radical species and small intermediates for the model results presented in Fig. 6. Shown specifically are the sum of key radical species that are associated with the low-temperature chemistry pathways of the large fuel alkyl radicals $-n$-heptyl and iso-octyl-, specifically alkylperoxy $\left(\mathrm{RO}_{2}\right)$ and ketohydroperoxide $(\mathrm{QOOH})$ radicals, as well as small species that promote low-temperature chemistry and autoignition, $\mathrm{OH}, \mathrm{HO}_{2}, \mathrm{H}_{2} \mathrm{O}_{2}$. The results show the radicals and small intermediates are crucial for not only fuel reactivity and autoignition, but also for releasing heat at the first stage of ignition. For example as seen in Fig. 7, $\mathrm{RO}_{2}$ and $\mathrm{HO}_{2}$ formation through bimolecular addition are key low-temperature reactions releasing heat at the first stage of ignition. Fig. 8 shows the shift from high levels of $\mathrm{C}_{7}$ and $\mathrm{C}_{8} \mathrm{RO}_{2}$ intermediates for PRF60 during the first stage of ignition to orders of magnitude lower levels of these species for PRF88 at early times in the cycle. The concentrations of radicals like $\mathrm{RO}_{2}$ are thus limited proxies for the heat release at the first stage of ignition.

There is no distinct first stage of ignition for PRF85 and PRF88, and the species time histories for these blends are similar. PRF100 did not exhibit autoignition at this case. Yet, as observed in Fig. 8, lowtemperature chemistry radicals are formed nonetheless for these blends, showing that even small amounts of fuels that exhibit low-temperature chemistry like $n$-heptane, when present in the PRF blends, will pass through these low-temperature pathways at conditions relevant to HCCI engines. It can be seen from that the radical formation for PRF100 follows PRF88 but despite reaching the same concentrations, the slower high temperature chemistry coupled with the reduction of the temperatures after TDC prohibits the thermal runaway and autoignition. In comparison with PRF85 and PRF88, PRF75 shows a significant increase in the concentrations of small radical species formed during low-temperature chemistry, such as $\mathrm{HO}_{2}$ and $\mathrm{H}_{2} \mathrm{O}_{2} . \mathrm{H}_{2} \mathrm{O}_{2}$ decomposition results in the production of $\mathrm{OH}$ radicals that cause thermal runaway and autoignition. For PRF60 and PRF0 the local maximum concentration of $\mathrm{OH}$ radicals corresponds to the low temperature heat release associated with the first stage of ignition.

Note the concentrations of $\mathrm{RO}_{2}$ radicals for both $\mathrm{C}_{7}$ and $\mathrm{C}_{8}$ correlate with each other in shape and in value for each PRF blend. This is particularly interesting because 1) iso-octane is much less reactive than $n$-heptane at low-temperatures; 2) the concentration of $n$-heptane is much lower than the concentration of iso-octane; and 3) the fraction of fuel consumed at the first stage of ignition, as observed for PRF60 in Fig. 6, for iso-octane is half that of $n$-heptane. These results provide evidence of the synergism of reactivity, as described by Vanhove et al.[21] and Karwat et al. [28], in which a highly reactive fuel promotes the reactivity of a less reactive fuel, and, conversely, in which a less reactive fuel non-linearly suppresses the reactivity of a highly reactive fuel.

As expected, the amount of $n$-heptane in the PRF blend is a key determinant of the magnitude of the low-temperature chemistry. If the concentrations of the low-temperature chemistry radicals were 
normalized by the amount of the respective fuel source in the binary blend, the results would show the fraction is much higher for $n$-heptane than for iso-octane; indicating a larger fraction of the $n$-heptane participates in the low temperature reaction pathways compared with iso-octane. Changing the blend ratio changes the absolute concentration as well as the shape of the evolution of $\mathrm{RO}_{2}$ and QOOH species, and $n$-heptane concentrations therefore control the distribution of heat release and phasing of PRFs.

\subsection{Effects of Intake Temperature and Pressure on PRF Blends}

As the amount of iso-octane in the PRF blend increases, the ignition delay time increases, as seen in Fig. 1. When coupled with the temperature decrease that occurs during the expansion stroke after TDC, increasing iso-octane content in the blend causes the engine phasing in the engine simulation to be significantly later even for small changes in the PRF blend, as seen in Fig. 6, e.g. for PRF85 and PRF88. Since the fuel consumption is more distributed in time as the amount of iso-octane in the PRF blend increases (seen in Fig 6), or, in other words, since less of the fuel is consumed quickly with increasing amounts of iso-octane in the PRF blend, small changes in thermodynamic conditions can lead to large changes in phasing after TDC for PRF blends with high fractions of iso-octane.

In order to understand the effects of temperature and pressure on fuel chemistry at realistic and fixed phasing conditions for a reciprocating engine, simulations with fixed engine phasing, specifically CA50 (which is the second stage of ignition for all practical purposes) set at $3.5^{\circ}$ after top-dead center (aTDC), were conducted. The simulations used a compression ratio of $C R=11.5$, intake pressure of $P_{\text {in }}=1$ bar, equivalence ratio of $\phi=0.33$ with air dilution and 5\% EGR for all cases. Fixing CA50 required changing the intake temperature for each PRF blend where the intake temperature was adjusted from $T_{\text {in }}=363 \mathrm{~K}$ for PRF60 to $T_{i n}=447 \mathrm{~K}$ for PRF88.

Fig. 9 presents the results of the simulations. The top panel shows the normalized mole fraction of $n$ heptane as a function of time in the system. A significant amount of $n$-heptane in PRF60 is consumed $(\sim 70 \%)$ at the first stage of ignition over a very short period of time ( $<3 \mathrm{CAD})$. As seen in the bottom panel, the fuel consumption occurs in the NTC temperature window, starting at $\sim 760 \mathrm{~K}$ and ending at $\sim 840 \mathrm{~K}$, with $6 \%$ of the overall heat release occurring in the first stage of ignition. For fuel blends above PRF75, there is negligible heat release at low temperatures, and only the autoignition event is observed. High intake temperatures are required for the high PRF numbers to maintain the combustion phasing at 3.5 $5^{\circ}$ TDC. The Arrhenius diagram presented in Fig 1 shows that at engine relevant conditions of approximately 10 bar, the highest temperature at which low-temperature chemistry occurs for these blends is $\sim 775 \mathrm{~K}$, and the difference between the second and first stages of ignition for PRF88 at these conditions is $\sim 47 \mathrm{~ms}$, which is too long to observe first stage heat release at the engine simulation conditions. 
The results of Fig. 9 can also be compared with expectations based on the temperature and pressure trajectories superimposed on the P-T-heat release diagrams for PRF0 and PRF100 shown in Fig. 4. Based on the data of Fig. 4, PRF100 would not experience any heat release during the first stage of ignition for $T_{i n}=423 \mathrm{~K}$, and higher intake temperatures would shift the T-P trajectory towards the top left corner of the diagram and further away from the NTC region. For PRF0, the data of Fig. 4 indicate a maximum heat release during the first stage of ignition of 18\%. The simulation results of Fig. 9 show the finite reaction time during compression as well as the lower $n$-heptane concentration for PRF60 yields heat release of $\sim 9 \%$ during the first stage of ignition.

For comparison purposes, simulation results for PRF75 at the same intake temperature of $363 \mathrm{~K}$ as PRF60 are also presented in Fig. 9 as the dot-dot-dashed lines. The results for PRF75 with $T_{\text {in }}=363 \mathrm{~K}$ show the first stage of ignition occurs at $\sim 770 \mathrm{~K}$, but the decreased amount of $n$-heptane in the fuel blend and the suppression of the low-temperature chemistry pathways due to the higher iso-octane concentration extends the duration of the second stage of ignition too long to maintain the phasing at $3.5^{\circ}$ aTDC. Consequently, autoignition never occurs for PRF75 with $T_{i n}=363 \mathrm{~K}$ due to quenching during expansion. Instead, the intake temperature must be increased to $405 \mathrm{~K}$ for PRF75 to maintain phasing at $3.5^{\circ}$ aTDC, which significantly reduces the heat release during the first stage of ignition, as depicted by the significantly longer consumption of $n$-heptane in the top panel of Fig. 9.

Karwat et al. [14] found in their experimental and computational work for $n$-heptane that 1) the amount of fuel consumed at the first stage of ignition and the amount of heat released at the first stage of ignition decreases with increasing temperature, and that 2) the higher the initial temperature, the longer the time between the first and second stages of ignition, until two-stage behavior disappears. From an engine operation standpoint that targets distributed heat release at a fixed engine speed, the intake temperature should be such that low temperature heat release occurs early enough before TDC to allow the low temperature chemistry time for heat release associated with two-stage ignition to occur. However, as the amount of $n$-heptane decreases with increasing PRF number, the intake temperature needs to be increased to accelerate the second stage of ignition, which tends to increase the time required for heat release at the first stage of ignition.

The effects of the low temperature chemistry are also apparent in the time histories of the intermediate and radical species. Specifically, the $\mathrm{RO}_{2}$ radicals for the fixed ignition phasing simulations, represented in Fig. 9, are compared with the results for the cases with higher compression ratio and fixed intake temperature $\left(C R=15, T_{\text {in }}=423 \mathrm{~K}, P_{\text {in }}=1 \mathrm{bar}\right)$ in Fig. 10 for PRF60, PRF75, and PRF88. The temperature profiles are also presented to highlight the temperature interval in which the radical species are being formed and consumed. Since PRF85 and PRF88 exhibited very similar trends, only PRF88 results are shown. The $\mathrm{RO}_{2}$ radicals for both $\mathrm{C}_{7}$ and $\mathrm{C}_{8}$ correlated with each other in shape and in value 
for each PRF blend, as shown in Fig. 8, therefore only $\mathrm{C}_{7} \mathrm{RO}_{2}$ are presented in Fig. 10. The results show the lower compression ratio $C R=11.5$ and lower intake temperatures $\left(T_{i n}=363 \mathrm{~K}\right.$ for PRF60 and $T_{\text {in }}=$ $405 \mathrm{~K}$ for PRF75) yield higher peak concentrations of $\mathrm{RO}_{2}$ radicals compared with the higher compression ratio and higher intake temperature conditions of $T_{\text {in }}$ of $423 \mathrm{~K}$ for $C R=15$. The lower $T_{\text {in }}$ for $C R=11.5$ increases the low temperature reactivity of PRF60 and PRF75. The timing of these concentration peaks align with the temperature increases due to low temperature heat release and this sharp increase in the temperature pushed the charge out of NTC region and the chain branching reactions stop. In comparison, PRF 88 does not exhibit a peak in the early stages and the concentration of the radicals increase monotonically until the thermal runaway and autoignition. The increases in intake temperature and compression ratio only affected the overall reaction kinetics of fuel consumption and the timing of ignition. The peak concentrations of $\mathrm{RO}_{2}$ and QOOH radicals (not shown here) did not change significantly.

Higher engine speeds reduce the residence time of the fuels at high temperatures and pressures, which dramatically changes the chemistry exhibited by the PRF blends. Simulations were performed at a higher engine speed conditions of 1800 RPM while maintaining the ignition phasing at $3.5^{\circ}$ aTDC by varying the intake temperature. As can be deduced from Fig. 1, decreasing the residence time of fuel/air mixtures requires higher intake temperatures and/or pressures to maintain fixed ignition timing. Furthermore, Fig.1 shows $n$-heptane and iso-octane have the same reactivity at high temperatures, regardless of pressure. For the 1800 RPM simulations, the intake temperatures required to fix the phasing at $3.5^{\circ}$ aTDC was virtually the same for all PRF blends, $T_{i n}=484-488 \mathrm{~K}$. The significantly reduced residence time in the NTC region at 1800 RPM and the higher intake temperatures resulted in no observable first stage of ignition for any fuel blend, including PRF60. Sjöberg and Dec [29] have observed similar trends in their experimental studies of PRF fuels during HCCI engine operation where increasing engine speed decreased the "cool-flame activity" or the low temperature chemistry of the PRF fuel blends. Sjöberg and Dec [29] conjectured that there was a limiting engine speed above which there would be no observable effects of low temperature chemistry ( 3000 RPM for PRF60).

\subsection{Additional Implications of Simulation Results}

In dynamic thermodynamic environments like reciprocating engines, autoignition events are outcomes of the cumulative effects of temperature and pressure on fuel/air mixtures. This is in contrast to studies conducted to examine the combustion kinetics at constant temperatures and pressures of fuel/air mixtures, like ignition experiments conducted in shock tubes and rapid compression facilities, in which dynamic thermodynamic conditions are intentionally minimized. It is valuable to understand the cumulative and integrated effects of state conditions on fuel reactivity, particularly for chemical kinetic 
models that have been deeply influenced by shock tube and rapid compression facility chemical kinetic studies. The Livengood-Wu autoignition integral [30] is a method that has been developed for the express purpose to include the effects of dynamic state conditions on ignition timing. As shown in Eq. (1), ignition is calculated by integrating the cumulative effects of fuel reactivity at each temperature and pressure condition the fuel/air mixture experiences prior to autoignition.

$$
1=\int_{t=0}^{t=t_{I G N}} \frac{\mathrm{d} t}{\tau(T, P)}
$$

For fuels with single stage heat release, this metric can be an effective way of predicting the autoignition event in engine environments [31], but the method, as it stands, does not account for fuels that exhibit LTHR and two-stage heat release.

In order to provide a more clear understanding of the effect of the range of intake temperatures that will allow different PRF blends to exhibit LTHR before TDC, the Livengood-Wu autoignition integral was adapted in this work to estimate the onset of the first stage of ignition and a heat release fraction associated with the first stage of ignition. The results quantify the sensitivity of low temperature chemistry to intake temperature and residence time. The autoignition integral was evaluated for an adiabatic motoring trace for $C R=11.5$, using the ignition delay values (previously calculated using the detailed reaction mechanism for the first stage of ignition, $\tau_{1}$, for a large range of PRF blends, temperatures and pressures), to identify the timing of the first stage of ignition $\boldsymbol{\theta}_{I G N, \mathbf{1}}$, at which the integral approaches unity, and the temperature at this onset of LTHR. The engine speed is scaled by the $\frac{\boldsymbol{d} \boldsymbol{t}}{\boldsymbol{d} \boldsymbol{\theta}}$, where $\theta$ is in crank angle degrees and the resulting expression is given in Eq. 2.

$$
\frac{\mathrm{dt}}{\mathrm{d} \theta} \cdot \int_{\theta=\mathrm{IVC}}^{\theta=\theta_{\mathrm{IGN}, 1}} \frac{1}{\tau_{1}(\mathrm{~T}, \mathrm{P})} \mathrm{d \theta}=1
$$

The heat release fraction of the LTHR is calculated using the same method described earlier to develop the results presented in Fig. 4.

The results for the modified autoignition integral are presented in Fig. 11 for PRF60 and PRF88 as a function of engine speed and $T_{i n}$ for a fixed compression ratio of $C R=11.5, P_{i n}=1 \mathrm{bar}$, and $\phi=0.3$. The regions in white represent the conditions in which the first stage of ignition would not occur before TDC. For PRF60 at an engine speed of 1300 RPM, Fig. 11 shows LTHR does not occur until $T_{\text {in }}$ is approximately $325 \mathrm{~K}$, and the first stage of ignition occurs close to TDC at this $T_{\mathrm{in}}$. As $T_{\text {in }}$ is increased at $1300 \mathrm{RPM}$, the first stage of ignition advances in time, until at $T_{\text {in }}$ of $\sim 400 \mathrm{~K}$, the first stage of ignition ceases to occur. The results indicate for PRF60, the first stage of ignition at $1300 \mathrm{RPM}$ for $T_{\text {in }}=400 \mathrm{~K}$ can produce a first stage heat release fraction of $<8 \%$. The changes in the characteristics and limits of the first state of ignition as a function of increased $T_{i n}$ are due to the changing reaction kinetics as seen in Fig. 1; as the temperature increases, the reaction chemistry moves out of the NTC region. The timing of the 
first stage of ignition is a non-linear function of residence time, and so is the amount of heat release at the first stage of ignition as seen in Fig. 11.

In essence, the contours of Fig. 11 depict the non-Arrhenius NTC behavior of Fig. 1 in metrics important to practical engine operation. As the engine speed increases, the residence time at each temperature decreases. And, as the PRF number increases, the concentration of iso-octane, which is much slower to react than and shows less NTC behavior compared to $n$-heptane, increases. Thus, as engine speed increases, LTHR occurs for a much wider engine operating range for PRF60 compared with PRF88. Further, at the same intake temperature and engine speed, the first stage of ignition moves closer to TDC for PRF88 when compared to PRF60. Fig. 11 provides a clear picture of the operating conditions within which multi-stage ignition can be used to maximize HCCI performance.

\section{Conclusions}

The results of the current work provide new understanding for trends observed in previous experimental studies of primary reference fuels at conditions where ignition is controlled by ignition chemistry, as well as a novel method to guide for future strategies to control heat release using ignition chemistry. In particular, this work focused on iso-octane and n-heptane as two hydrocarbons with high confidence in the chemical mechanisms. Extension of these methods to more complex fuels is necessary and a valuable area for future work. The primary conclusions of the study are as follows.

The fixed phasing simulations indicate that for low PRF number blends (e.g. PRF60), more lowtemperature chemistry, i.e. lower intake air temperature, is required to fix phasing at an optimum CAD. This result is consistent with experimental observations by Sjöberg and Dec [29], who found intake temperatures had to be "decreased drastically" as low temperature chemistry increased with lower PRF number blends to maintain combustion phasing in their HCCI engine study. For higher PRF number blends (e.g. PRF75), higher intake temperatures are required to move the reaction kinetics of the fuel into the high temperature regime in order to fix the phasing at CAD suitable for practical engine operation. Interestingly, given nominal temperature and pressure trajectories experienced by PRF blends in an engine, it may be that only the first stage of ignition exhibits the non-linearity observed in the negative temperature coefficient region, while the timing of the autoignition event monotonically advances with the increasing temperatures and pressures cause by the compression process. Increasing intake temperature conditions to ensure adequate phasing will decrease low temperature heat release from both PRF components, thus making it difficult to distribute heat release in time using LTHR chemistry.

Generally, fuel components that exhibit low temperature chemistry within practical engine operating conditions must be present to distribute heat release in an engine operating at kinetically limited and not mixing limited conditions. At the conditions important for HCCI engine operation, the interplay between reactions that are exothermic and endothermic dictates low temperature chemistry and two-stage ignition. 
For example, alkylperoxy and hydroperoxy radical formation through bimolecular addition are key lowtemperature reactions that release heat at the first stage of ignition for $n$-heptane and low PRF number blends. Yet these species are also formed by high PRF number blends that do not display low temperature heat release or multi-stage ignition behavior during compression. Thus, low temperature chemistry radicals like $\mathrm{C}_{7} \mathrm{RO}_{2}$ species are not uniquely indicative of low temperature heat release, but they are formed at earlier times, higher rates and higher concentrations with PRF blends with higher fractions of $n$-heptane.

As in the current work and previous studies such as Mehl et al. [16], superimposing temperature and pressure trajectories expected in engines onto P-T-ignition delay time and P-T-heat release maps generated at constant state conditions provides limiting values for ignition timing and the heat release. However, the modified Livengood-Wu integral introduced in this work provides more appropriate limiting values (since the data include the integrated effects of the state conditions) for the first stage of ignition as a function of engine operating parameters. The results of the modified Livengood-Wu analysis presented in this work show the effectiveness of low temperature heat release is limited to lower engine speeds (e.g. 5\% overall heat release in the first stage of ignition requires speeds <2500 RPM) and lower PRF number blends (PRF60 and below). Further, the modified Livengood-Wu integral approach can be easily applied to quantify the effects of different fuel chemistries on low temperature heat release to enable the design and interpretation of fueling strategies of fuel blends.

\section{Acknowledgements}

The authors would like to thank Dr. V. Rapp for sharing her experimental HCCI engine data and Dr. George Lavoie for his thoughtful discussions on this subject. The authors acknowledge the generous financial support of the U.S. Department of Energy, Office of Basic Energy Sciences, Contract No. DESC0002645.

\section{References}

[1] S. Saxena and I. D. Bedoya, Prog. Energy Combust. Sci., Jun. 2013.

[2] E. J. Silke, W. J. Pitz, C. K. Westbrook, M. Sjöberg, et al., SAE Int. J. Fuels Lubr., vol. 1, no. 1, pp. 12-25, 2008.

[3] G. T. Kalghatgi and R. a Head, Int. J. Engine Res., vol. 7, no. 3, pp. 215-236, Jun. 2006.

[4] A. Lewis, E. Ortiz-Soto, G. Lavoie, and D. N. Assanis, Int. J. Engine Res., May 2014.

[5] C. K. Westbrook, W. J. Pitz, and W. R. Leppard, SAE Tech. Pap., no. 912314, 1991. 
[6] Y. Yang, J. E. Dec, N. Dronniou, M. Sjöberg, et al., SAE Int. J. Engines, vol. 4, no. 1, pp. 19031920, Apr. 2011.

[7] Y. Yang, J. E. Dec, N. Dronniou, and W. Cannella, SAE Int. J. Engines, vol. 5, no. 3, pp. 10751088, Apr. 2012.

[8] H. J. Curran, P. Gaffuri, W. J. Pitz, and C. K. Westbrook, Combust. Flame, vol. 114, no. 1-2, pp. 149-177, 1998.

[9] H. J. Curran, P. Gaffuri, W. J. Pitz, and C. K. Westbrook, Combust. Flame, vol. 129, no. 3, pp. 253-280, 2002.

[10] H. J. Curran, W. J. Pitz, C. K. Westbrook, G. V. Callahan, et al., Symp. Combust., vol. 27, no. 1, pp. 379-387, Jan. 1998.

[11] P. Dagaut, M. Reuillon, and M. Cathonnet, Combust. Flame, vol. 101, no. 1-2, pp. 132-140, 1995.

[12] P. a. Glaude, V. Conraud, R. Fournet, F. Battin-Leclerc, et al., Energy \& Fuels, vol. 16, no. 5, pp. 1186-1195, Sep. 2002.

[13] P. Dagaut, M. Reuillon, and M. Cathonnet, Combust. Sci. Technol., vol. 95, no. 1-6, pp. 233-260, 1994.

[14] D. M. A. Karwat, S. W. Wagnon, M. S. Wooldridge, and C. K. Westbrook, Combust. Flame, 2013.

[15] C. K. Westbrook, W. J. Pitz, O. Herbinet, H. J. Curran, et al., Combust. Flame, vol. 156, no. 1, pp. 181-199, 2009.

[16] M. Mehl, T. Faravelli, F. Giavazzi, E. Ranzi, et al., Energy \& Fuels, vol. 20, no. 6, pp. 2391-2398, 2006.

[17] M. Mehl, T. Faravelli, E. Ranzi, D. Miller, et al., Proc. Combust. Inst., vol. 32, no. 2, pp. $2843-$ 2850, 2009.

[18] M. Mehl, W. J. Pitz, M. Sjöberg, and J. E. Dec, SAE Tech. Pap., no. 2009-01-1806, 2009.

[19] M. Mehl, W. J. Pitz, C. K. Westbrook, and H. J. Curran, Proc. Combust. Inst., vol. 33, no. 1, pp. 193-200, 2011.

[20] H. Wang, E. Dames, B. Sirjean, D. A. Sheen, et al., JetSurF version 2.0. [Online]. Available: http://web.stanford.edu/group/haiwanglab/JetSurF/JetSurF2.0/index.html.

[21] G. Vanhove, G. Petit, and R. Minetti, Combust. Flame, vol. 145, no. 3, pp. 521-532, May 2006.

[22] M. M., W. J. Pitz, and C. K. Westbrook, Lawrence Livermore National Laboratory. [Online]. Available: https://combustion.llnl.gov/mechanisms/surrogates/gasoline-surrogate.

[23] CHEMKIN, "Reaction Design CHEMKIN.” 2013. 
[24] I. Truedsson, M. Tuner, B. Johansson, and W. Cannella, SAE Int. J. Engines, vol. 5, no. 3, pp. 1089-1108, 2012.

[25] A. D. B. Yates, A. Swarts, and C. L. Viljoen, SAE Tech. Pap., no. 2005-01-2083, 2005.

[26] V. H. Rapp, W. J. Cannella, J.-Y. Chen, and R. W. Dibble, Combust. Sci. Technol., vol. 185, no. 5, pp. 735-748, May 2013.

[27] J. B. Heywood, Internal Combustion Engine Fundamentals. McGraw-Hill, 1988.

[28] D. M. A. Karwat, S. W. Wagnon, M. S. Wooldridge, and C. K. Westbrook, J. Phys. Chem. A, vol. 116, no. 51, pp. 12406-21, Dec. 2012.

[29] M. Sjöberg and J. E. Dec, SAE Tech. Pap., no. 2003-01-3173, 2003.

[30] J. C. Livengood and P. C. Wu, Symp. Combust., vol. 5, no. 1, pp. 347-356, Jan. 1955.

[31] A. Babajimopoulos, G. A. Lavoie, and D. N. Assanis, Combust. Sci. Technol., vol. 179, no. 9, pp. 2039-2063, 2007. 


\section{List of Figures}

Fig. 1. Adiabatic constant volume simulation results for ignition delay time for PRF blends. Lines represent 10 bar and symbols represent 25 bar simulations. When two stages of ignition were observed, the open symbols and dotted lines indicate the first stage of ignition and closed symbols and solid lines indicate the second stage of ignition. The equivalent time in crank angle degrees is shown on the right axis for an engine speed of 600 RPM.

Fig. 2. Schematic describing the reaction pathway behavior of alkanes, after the work by Curran et al. [8] The low temperature pathway is represented by the bottom portion of the schematic which either leads to chain propagation or low temperature branching.

Fig. 3. Reactivity contour maps of ignition times for PRF0 (left) and PRF100 (right) fuels. The top and bottom panels present the first and second stages of ignition, respectively. The dashed line represents the range of pressures and temperatures experienced during a compression stroke for $C R=12, T_{\text {in }}=423 \mathrm{~K}$ and $P_{i n}=1$ bar, assuming isentropic compression for a fuel/air mixture with $\phi=0.33$.

Fig. 4. Contour maps of the fractional heat release associated with the first stage of ignition for PRF0 (left) and PRF100 (right) for the simulation conditions and compression stroke of Fig. 3.

Fig. 5. Comparison of experimental and computational results for combustion phasing for different PRF blends. Solid symbols represent CA50 determined from experiments by Rapp et al. [26] and open symbols represent the $d P / d \theta_{\max }$ results from the slider-crank simulations.

Fig. 6. Model predictions for pressure and accumulated heat release (left panel) and temperature and fraction of fuel consumption (right panel) of PRF blends with $C R=12, T_{\text {in }}=423 \mathrm{~K}, P_{\text {in }}=1$ bar.

Fig. 7. Model predictions for heat production and heat removal per reaction for PRF60 for the model conditions of Fig. 6. The left panel highlights the time associated with the first stage of ignition, and the right panel presents the heat release at autoignition.

Fig. 8. Model predictions of important intermediate and radical species of PRF blends with $C R=12, T_{i n}=$ $423 \mathrm{~K}, P_{\text {in }}=1$ bar.

Fig. 9. Model predictions for $T$ and heat release fraction (bottom panel) and normalized $n$-heptane mole fraction of PRF blends (top panel) with the same combustion phasing. The combustion phasing was set by changing the intake temperature for each fuel for $C R=11.5, P_{i n}=1 \mathrm{bar}$, and $\phi=0.33$. The simulation results for PRF 85 and 88 are nearly identical and result in nearly superimposed lines.

Fig. 10. Comparison of model predictions of $C_{7} R O 2$ intermediate speicies for PRF60, PRF75, and PRF88. Solid lines represent the blends with the same combustion phasing at $\mathrm{CR}=11.5$ and $P_{\text {in }}=1$ bar and the dashed lines represent blends with $\mathrm{CR}=15, T_{\text {in }}=423 \mathrm{~K}, P_{\text {in }}=1 \mathrm{bar}$.

Fig. 11. Model predictions for the phasing of the first stage of heat release and the fraction of the first stage to overall heat release based on the modified Livengood-Wu autoignition integral for PRF60 and PRF88. Simulation conditions of $C R=11.5, \phi=0.33$, and $P_{\text {in }}=1$ bar. 


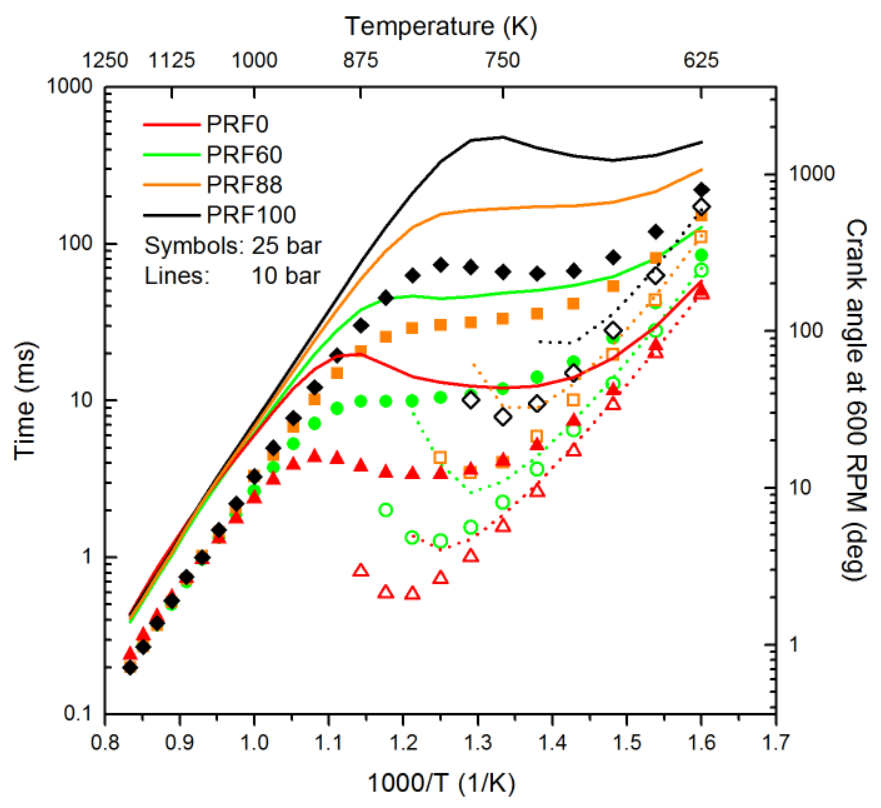

Fig. 1. Adiabatic constant volume simulation results for ignition delay time for PRF blends. Lines represent 10 bar and symbols represent 25 bar simulations. When two stages of ignition were observed, the open symbols and dotted lines indicate the first stage of ignition and closed symbols and solid lines indicate the second stage of ignition. The equivalent time in crank angle degrees is shown on the right axis for an engine speed of 600 RPM. 


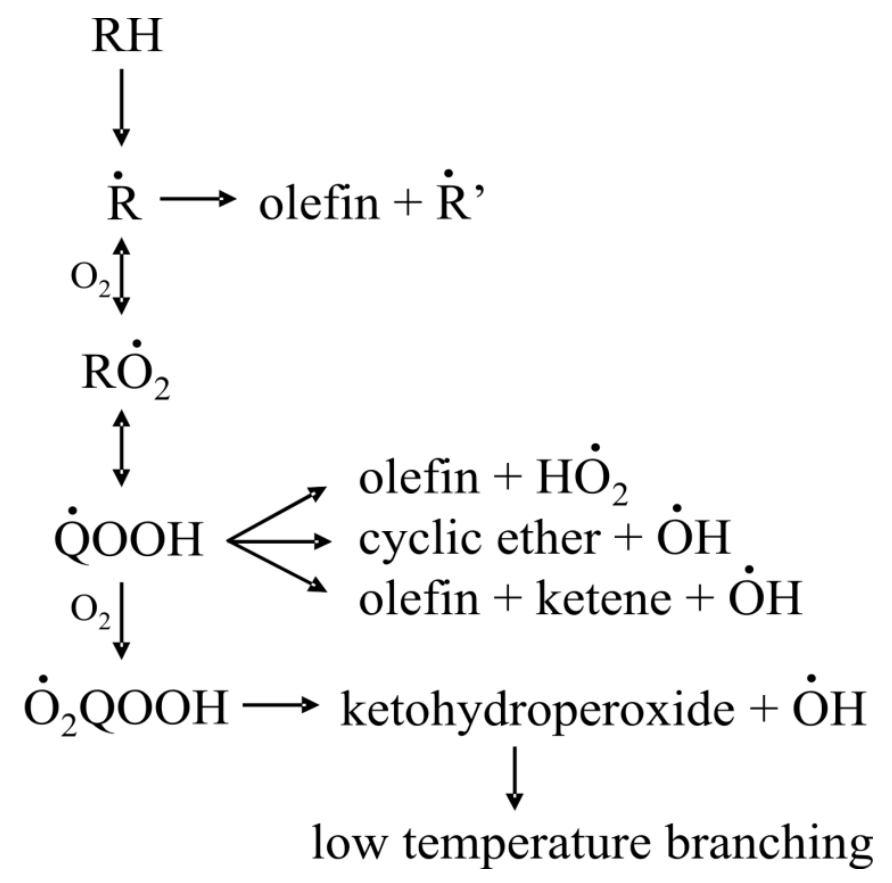

Fig. 2. Schematic describing the reaction pathway behavior of alkanes, after the work by Curran et al.[8]. The high temperature pathway is represented by the top portion of the schematic forming olefin $+\dot{\boldsymbol{R}}$ '. The low temperature pathway is represented by the bottom portion of the schematic which either leads to chain propagation or low temperature branching. 

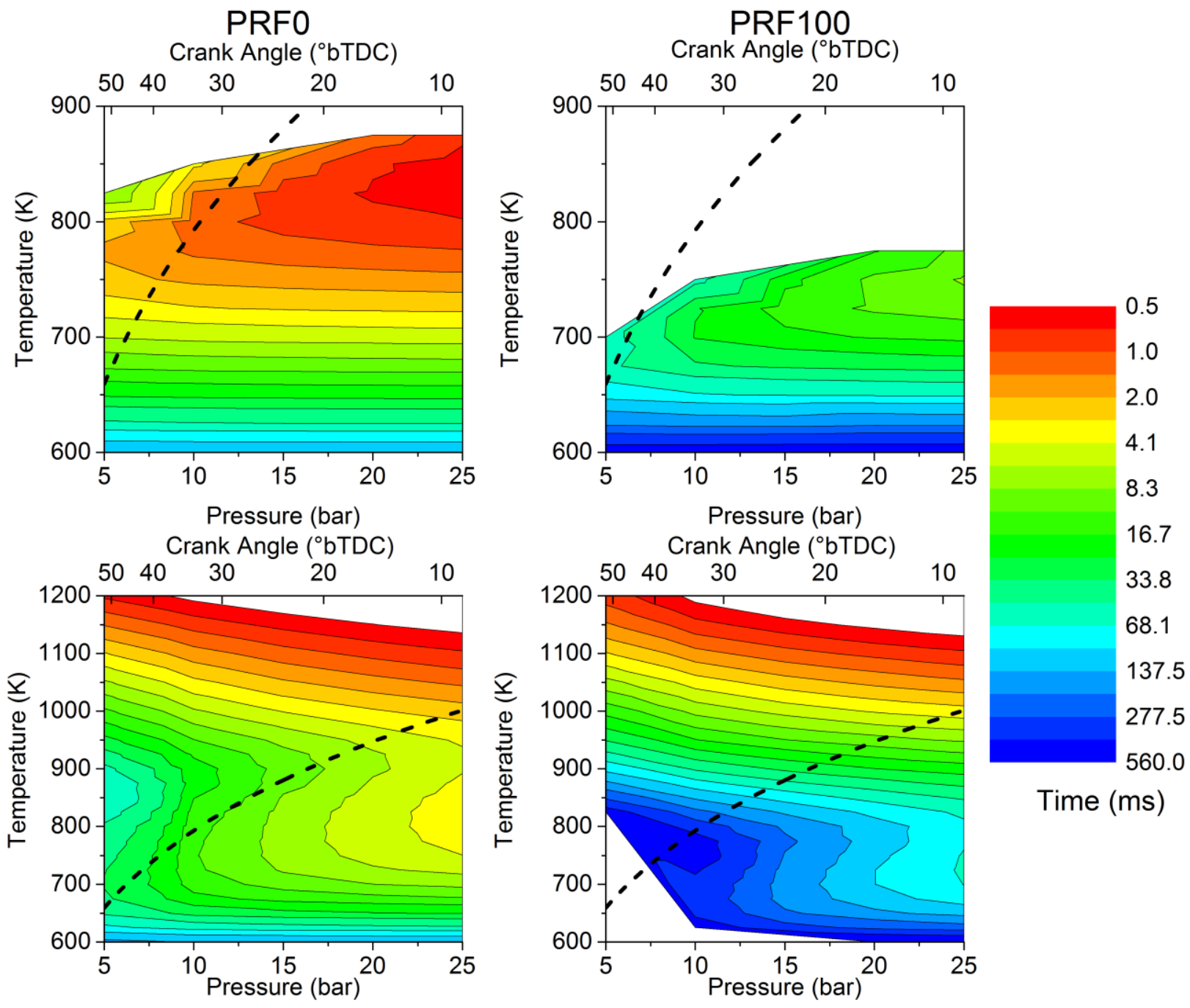

Fig. 3. Reactivity contour maps of ignition times for PRF0 (left) and PRF100 (right) fuels. The top and bottom panels present the first and second stages of ignition, respectively. The dashed line represents the range of pressures and temperatures experienced during a compression stroke for $C R=12, T_{\text {in }}=423 \mathrm{~K}$ and $P_{i n}=1$ bar, assuming isentropic compression for a fuel/air mixture with $\phi=0.33$. 

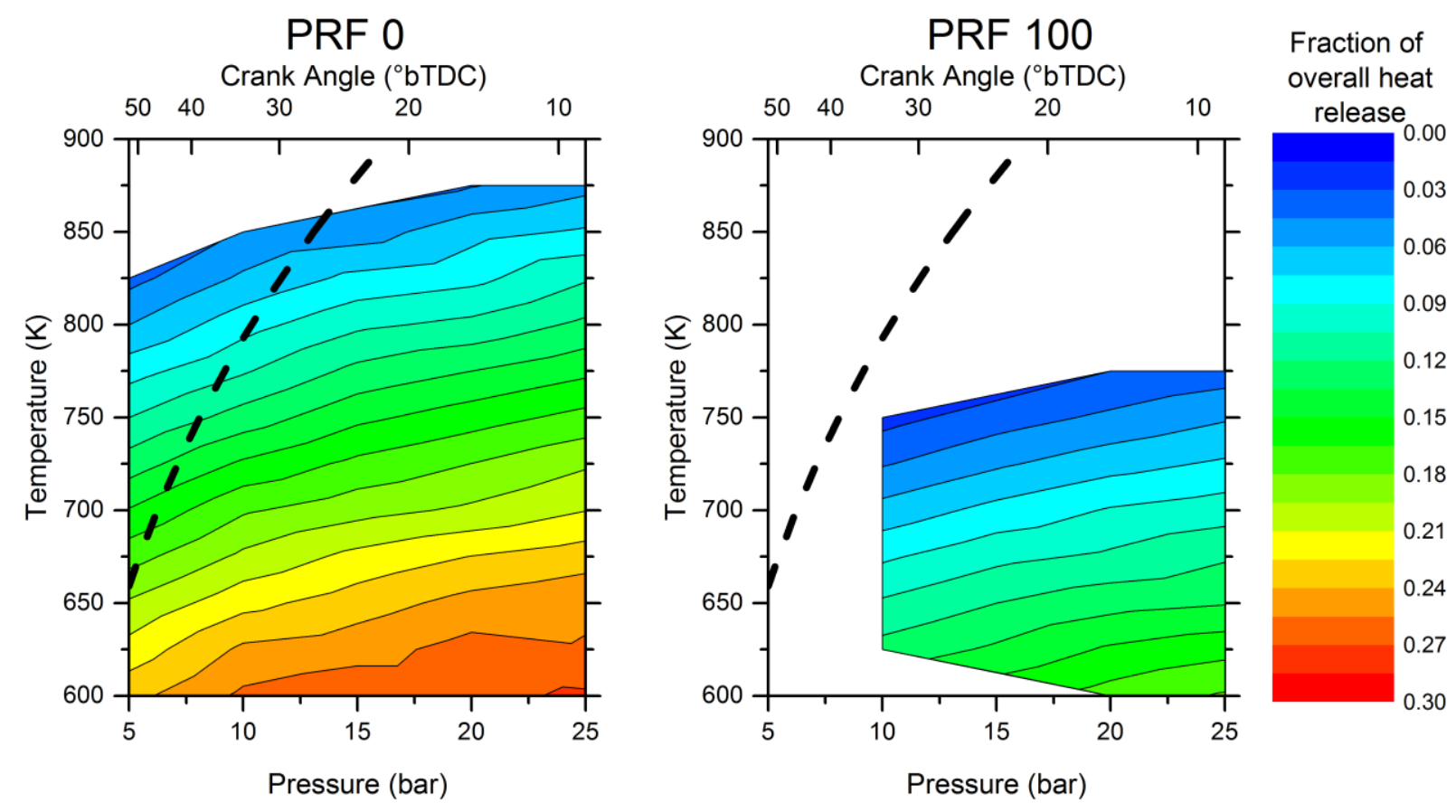

Fig. 4. Contour maps of the fractional heat release associated with the first stage of ignition for PRF0 (left) and PRF100 (right) for the simulation conditions and compression stroke of Fig. 3. 


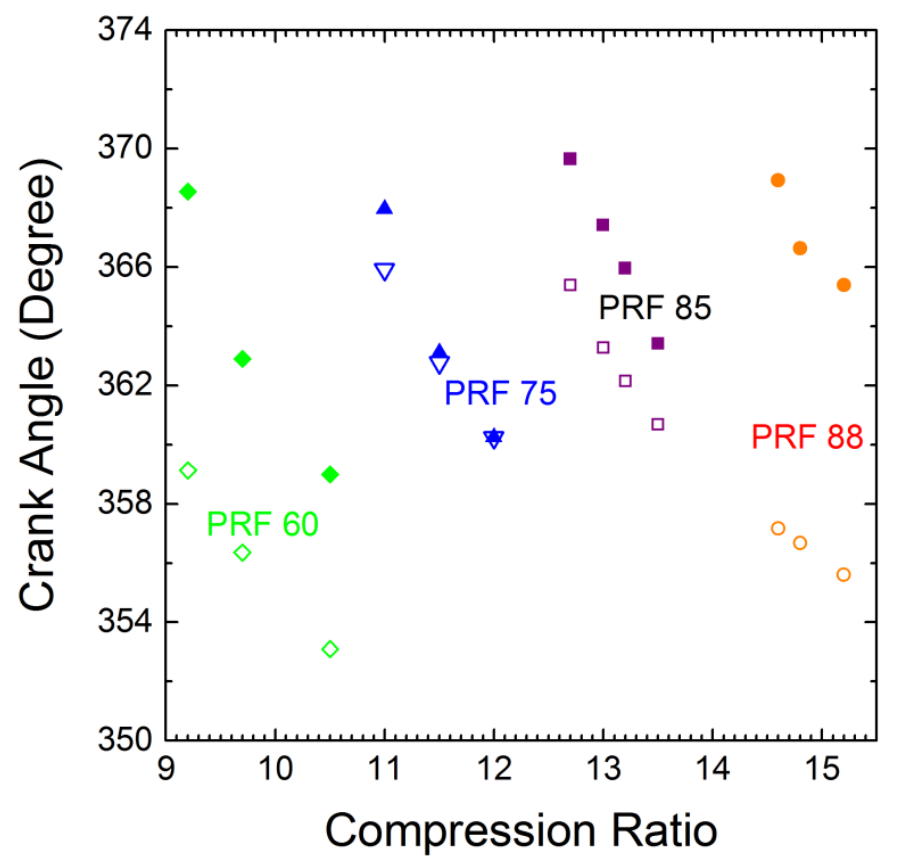

Fig. 5. Comparison of experimental and computational results for combustion phasing for different PRF blends. Solid symbols represent CA50 determined from experiments by Rapp et al. [26] and open symbols represent the $\mathrm{d} P / \mathrm{d} \theta_{\max }$ results from the slider-crank simulations. 

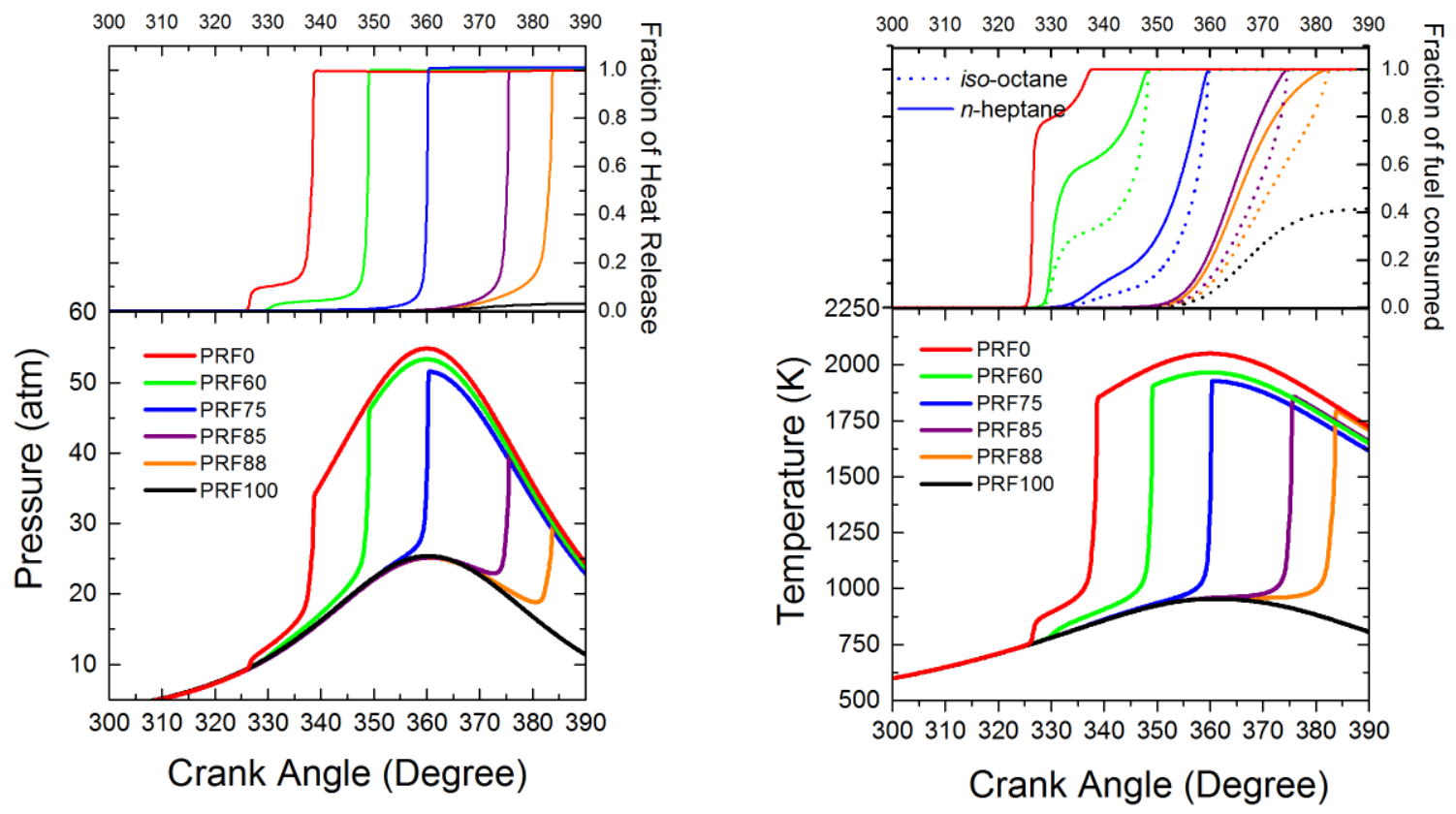

Fig. 6. Model predictions for pressure and accumulated heat release (left panel) and temperature and fraction of fuel consumption (right panel) of PRF blends with $C R=12, T_{\text {in }}=423 \mathrm{~K}, P_{\text {in }}=1$ bar. 

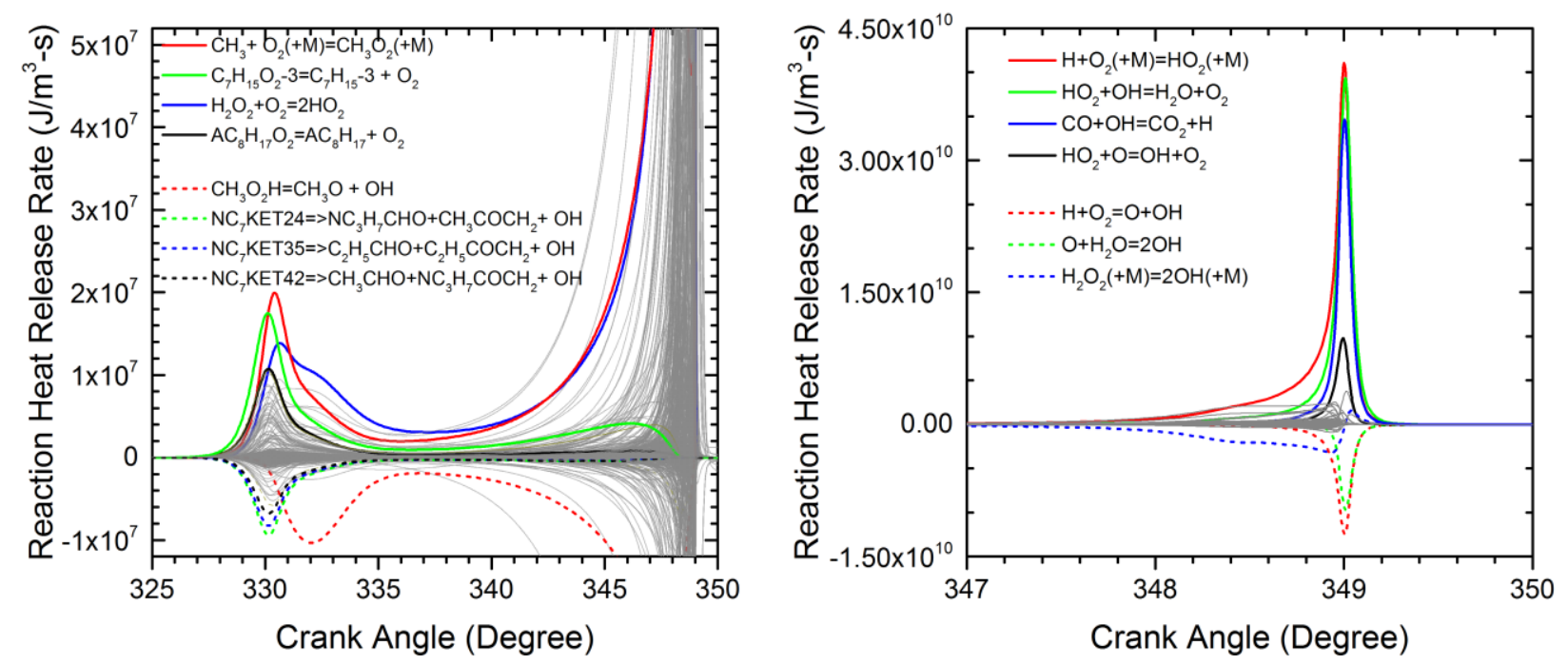

Fig. 7. Model predictions for heat production and heat removal per reaction for PRF60 for the model conditions of Fig. 6. The left panel highlights the time associated with the first stage of ignition, and the right panel presents the heat release at autoignition. 

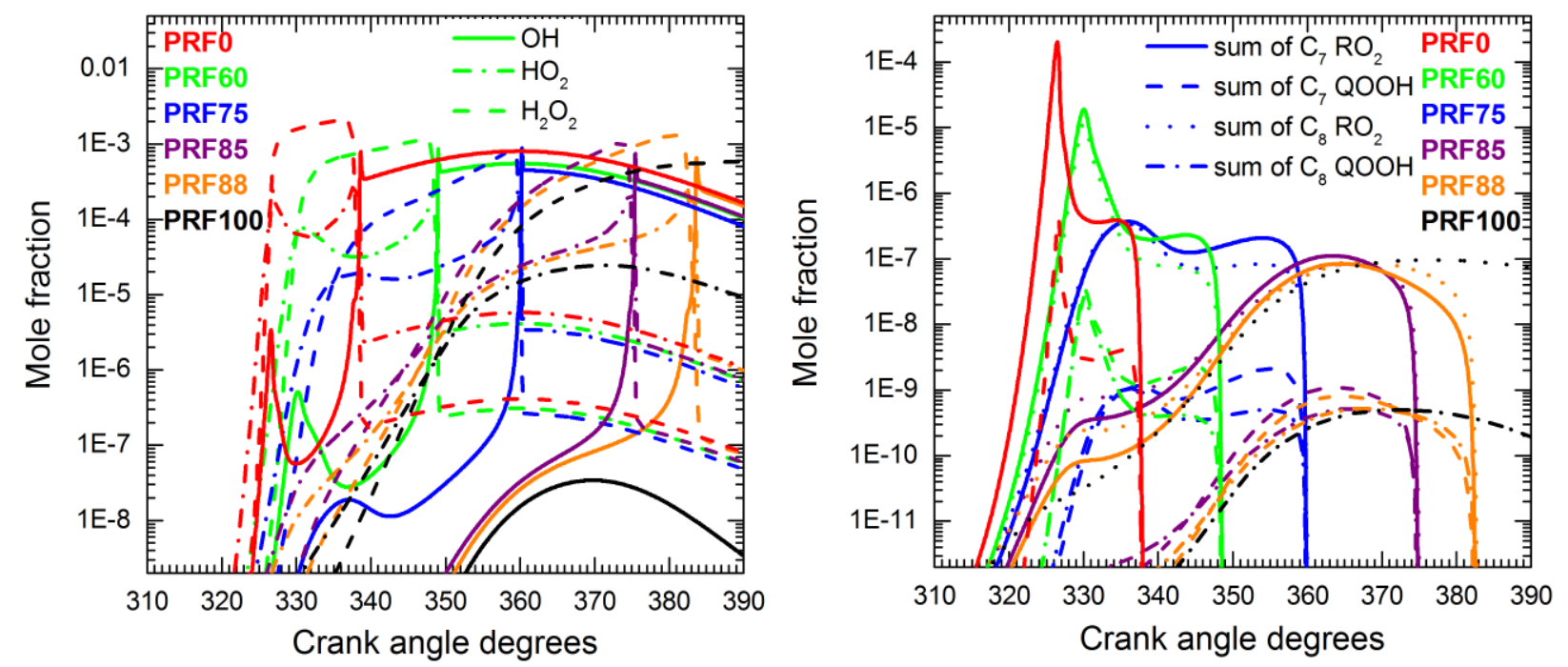

Fig. 8. Model predictions of important intermediate and radical species of PRF blends with $\mathrm{CR}=12, T_{\text {in }}=$ $423 \mathrm{~K}, P_{\text {in }}=1$ bar. 


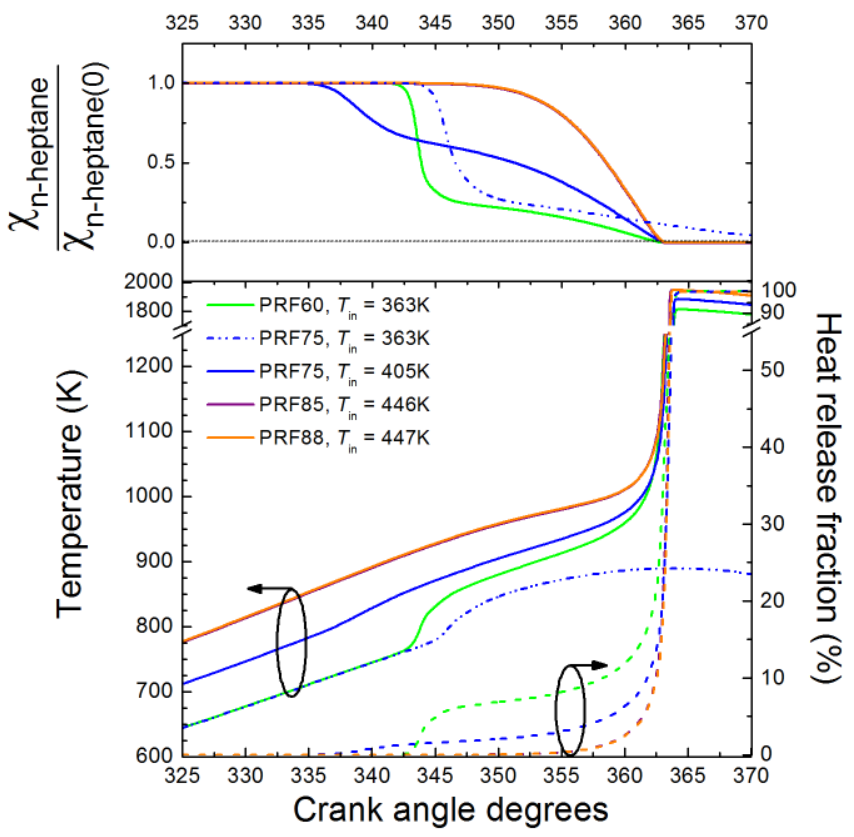

Fig. 9. Model predictions for $T$ and heat release fraction (bottom panel) and normalized $n$-heptane mole fraction of PRF blends (top panel) with the same combustion phasing. The combustion phasing was set by changing the intake temperature for each fuel for $\mathrm{CR}=11.5, P_{\text {in }}=1 \mathrm{bar}$, and $\phi=0.33$. The simulation results for PRF 85 and 88 are nearly identical and result in nearly superimposed lines. 


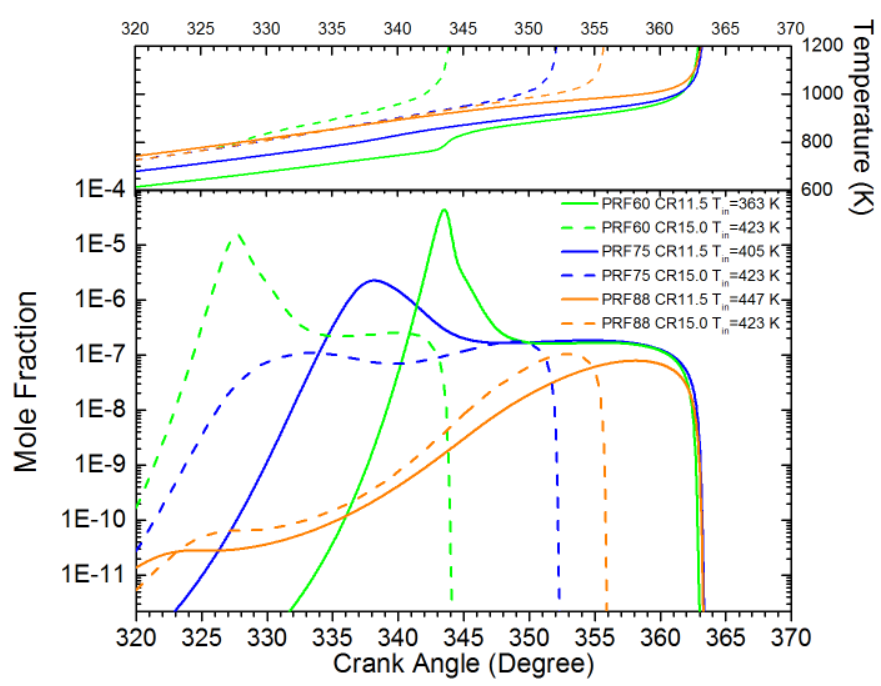

Fig. 10. Comparison of model predictions of $\mathrm{C}_{7} \mathrm{RO}_{2}$ intermediate speicies for PRF60, PRF75, and PRF88. Solid lines represent the blends with the same combustion phasing at $\mathrm{CR}=11.5$ and $P_{\text {in }}=1 \mathrm{bar}$ and the dashed lines represent blends with $\mathrm{CR}=15, T_{\text {in }}=423 \mathrm{~K}, P_{\text {in }}=1 \mathrm{bar}$. 


\section{Phasing of the $1^{\text {st }}$ stage of heat release}
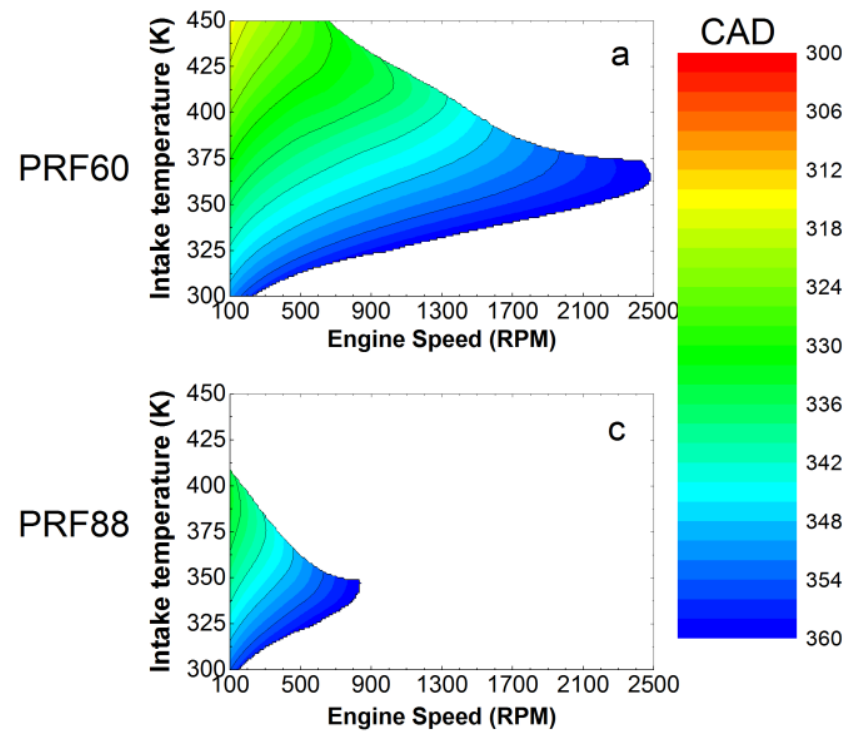

Fraction of overall heat release occuring at $1^{\text {st }}$ stage

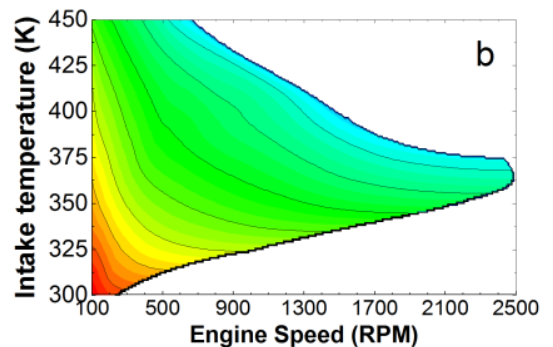

fraction
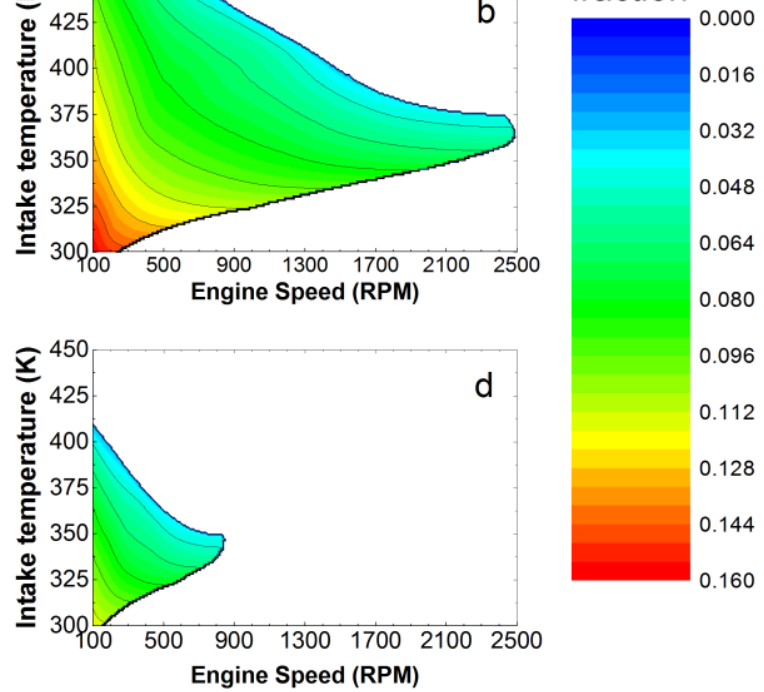

Fig. 11. Model predictions for the phasing of the first stage of heat release and the fraction of the first stage to overall heat release based on the modified Livengood-Wu autoignition integral for PRF60 and PRF88. Simulation conditions of $C R=11.5, \phi=0.33$, and $P_{\text {in }}=1$ bar. 